\title{
EXPLOITING THE INFORMATION OF STOCK MARKET TO FORECAST EXCHANGE RATE MOVEMENTS
}

\author{
Manish KUMAR*
}

\begin{abstract}
The present study examines dynamic relation between stock index and exchange rate by using the daily data for India. The empirical evidence suggests that there is no long-run relationship; however, there is bidirectional causality between stock index and exchange rates. The findings of the causality tests strongly support portfolio or macroeconomic approach on the relationship between exchange rates and stock prices. An attempt is also made to forecast daily returns of INR/USD exchange rates by exploiting the information of causal relationship between exchange rates and stock index using Vector autoregression (VAR) model. VAR's out-of-sample performance is benchmarked against the traditional ARIMA model. The potential of the two models are rigorously evaluated by employing a cross-validation scheme and statistical metrics like mean absolute error, root mean square error and directional accuracy. Out-of-sample performance shows that VAR model is robust, and consistently produces superior predictions than ARIMA model.
\end{abstract}

Keywords: Stock Prices; Exchange Rates; Bivariate Causality; Forecasting.

JEL Classification: C22; C52; C53; F31; G10

\section{Introduction}

The foreign exchange market has grown remarkably in last few decades. The major factors which have contributed to the phenomenal growth of currency markets are the introduction of floating exchange rates and the swift development of global trading markets. Foreign exchange markets and exchange rates have been characterized by the dramatic changes over time, as a result of market crashes or rallies, changes in economic policy and business cycles. Such changes make the exchange rate unpredictable, volatile, noisy, nonstationary and chaotic. However, exchange rates play a critical role in determining the success of many businesses and financial institutions around the globe. Thus, the accurate prediction of exchange rate will largely benefit the multinational firms and financial institutions.

However, predicting the direction of the movement of exchange rates is considered as the challenging task. The earlier empirical studies [Meese and Rogoff, $1983 \mathrm{a}, \mathrm{b}, 20-24$ ] and [Alexander and Thomas, 1987, 63-64] on exchange rate forecasting suggest that exchange India.

* Manish KUMAR (manishkumar_iitm@yahoo.co.in), PhD student, "Indian Institute of Technology Madras", 
rates are unpredictable. These studies concludes that the naïve random walk model outperformed the time series, structural and econometric models even when time-varying parameters were incorporated into the models. The findings of Meese and Rogoff have been supported in many subsequent studies [Alexander and Thomas, 1987, 63-64], [Gandolfo et al., 1990, a, b, 990, 1-10], and [Sarantis and Stewart, 1995 a, b, 201-215]. In most of the studies, forecast performance assessment have been made using root mean square error (RMSE), mean absolute error (MAE), mean absolute percentage error (MAPE) or Theil's coefficient.

However, the few studies [Woo, 1985, 1-16], [Schinasi and Swami, 1989, 373-393] contradicted the findings of earlier studies. The results of these studies show their model outperform the naïve random walk model of the exchange rate for certain time periods and currencies. The result of suggests that because of problems of non-stationarity, previous empirical models of exchange rates are liable to have been inappropriately implemented. Thus, the non-stationary time series should be transformed to stationarity using suitable transformation measure.

Thus, Auto regressive Integrated Moving Average (ARIMA) model have been used to forecast various stationary financial time series. However, ARIMA is a univariate model and is developed based on the hypothesis that the time series being forecasted are linear and stationary. Several research articles [Baillie and McMahon, 1989], [Hsieh, 1989, 359-364] and [Hong and Lee, 2003, 1058-1060] have shown that changes in exchange rates are nonlinearly dependent. Thus, most of the recent studies [Weigend et al., 1991, 879-882], [Kuan and Liu, 1995, 357-364], [Brooks, 1997, 135-142], [Gencay, 1999, 99-103], [Qi and Wu, 2003, 623-630], [Chen and Leung, 2004, 1049-1055] etc., have used nonlinear models like artificial neural networks to forecast the exchange rates and find the results in favor of neural network.

In Indian context, [Panda and Narshimhan, 2003, 195-199] compared the efficiency of a backpropagated neural network with linear autoregressive and random walk models in the one-step-ahead prediction of daily Indian rupee/US dollar exchange rate. The authors concluded that the results were mixed and they did not find any winner model between neural network and linear autoregressive model. [Manish and Thenmozhi, 2004, 16-36, 2005] used ANN to forecast the INR/USD and INR/Euro, and compared the results against the ARIMA model. The empirical results suggest that ANN outperformed ARIMA.

Almost all studies in the literature adopted the practice of using neural networks to forecast time series, and compared it with different benchmark models. There are certain drawbacks in earlier studies. Though, the previous studies in exchange rate forecasting focus on out-of-sample performance, using multi-step-ahead and one-step-ahead forecasting methods, most studies arbitrarily split the available data into a training (in-sample) set for model construction and a test (out-of-sample) set for model validation, which leads to two related problems. First, it may introduce bias in model selection and evaluation, in that the characteristics of the test data set may be quite different from those of the training data. Second, it ignores the effect of sample size. The differences in performance of models are likely to be a result of variation in the time frame and the number of observations used. Due to high volatility and chaotic dynamics of exchange rates, the effects of sampling variation can be a major factor influencing the out-of-sample performance.

In most studies, the degree of accuracy and the acceptability of forecasting models were measured by the estimate's deviations from the observed values, and have not considered turning-point forecast capability using sign and direction test. [Leung et al., 2000, 175- 
178] in his study suggested that depending on the investors' trading strategies, forecasting methods based on minimizing forecast error may not be adequate to meet their objectives. In other words, trading driven by a certain forecast with a small forecast error may not be as profitable as trading guided by an accurate prediction of the direction or sign of return. Hence, the competing models must be evaluated not only in terms of MSE, MAE, etc, but also in terms of sign and direction test.

In most of the earlier studies, past lagged returns and technical indicators have been used as input to the neural network models. However, there are some recent studies [Corte $e t$ al., 2007, 10-14], [Rime et al., 2007, 8-12], [An-Pin Chen et al., 2008, 295-296] which use macroeconomic fundamentals as the independent variables in their econometric models to forecast exchange rates. Another area of research that has, until recently, been under researched involves the role of stock prices in determining exchange rates. Most of the studies [[Phylaktis and Ravazzollo, 2005, 1051-1052], [Doong et al., 2005, 120-122], [Vygodina, 2006, 219-222], [Pan et al., 2007, 15-22], [Ai-Yee Ooi, 2009, 95-97], [Aydemir and Demirhan, 2009, 214] etc.,] have reported causality from stock prices to exchange rates. Their results support the presence goods market approach or portfolio approach.

Moreover, numerous earlier articles used a different set of macroeconomic variables, technical indicators, etc to develop forecasting model. They have not considered stock prices data as possible explanatory variables. The portfolio approach theory suggests that stock prices may influence movements in exchange rates, through portfolio adjustments (inflows/outflows of foreign capital). If there is a persistent upward trend in stock prices, inflows of foreign capital would rise. A downward trend would diminish the domestic investor's wealth, leading to a fall in demand for money and lower interest rates - causing capital outflows that would result in currency depreciation. Therefore, as per the portfolio approach, stock prices would lead exchange rates [Tabak, 2006, 1376-1377].

Given this notion, the present study overcomes the drawback identified in the earlier study by developing a forecasting model to predict one step ahead of daily returns of the Indian Rupee (INR) Versus U.S.A Dollar (USD). In doing so, we examine the dynamic relations between stock index and exchange rates using linear granger causality tests for Indian market. In addition, we also use unit root and cointegration tests to analyze the long run equilibrium relationship between the two variables. In this study we concentrate on the macro level issues and contribute to the literature in the following ways.

The study exploits the dynamic linkage between stock price and exchange rate and uses the results granger causality test for selecting the important inputs for forecasting foreign exchange rates. We have considered two different types of the time-series models to forecast INR/USD returns. The first type of the time-series models is the simple univariate ARIMA model. The second type is the VAR (Vector Autoregressive) model approach.

In this study, we use a three-step empirical framework for examining dynamic relationships between exchange rates and stock index. In first step, we tests for the unit root, heteroscedasticity and cointegration for the two series. Next, we investigate the short term linear dynamic linkages between exchange rates and stock index. In last step, we eradicate the heteroscedasticity effect from the two series and again perform the linear granger causality tests.

To tackle these problems of sampling variation, this study, employs a cross-validation methodology to examine the out-of-sample performance of the two time series models. Cross-validation is a resampling technique, which uses multiple in-sample and out-of- 
sample data sets to examine the sample size effect and the effect of structural change of the data on the performance of the forecasting model.

Three different criteria are used to evaluate forecasting performance of the time series models. In addition to mean absolute error (MAE) and root mean square error (RMSE), the two models have been rigorously evaluated based on the directional accuracy. The directional accuracy measures the degree to which the forecast correctly predicts the direction of change in the actual INR/USD exchange rate returns.

In recent years, there is more interest and research on Indian market data due to the country's rapid growth and potential opportunities for investors. It is estimated that foreign investment in the Indian stock markets may cross $\$ 10$ billion-mark by the end of September 2009. Parallel to this, many firms that comprises the stock index (S\&P CNX Nifty Index of National Stock Exchange) have American Depository Receipts (ADR's) or General Depository Receipts (GDR's) which are traded on the NYSE, NASDAQ or on non-American exchanges. Over the years, Indian Rupee is gradually moving towards full convertibility. The two-way fungibility of ADRs/GDRs allowed by RBI has also possibly enhanced the linkages between the stock and foreign exchange markets in India. This background makes the study more interesting and worthy to investigate, whether the dynamic linkages between INR/USD and stock market index in India can be exploited to build a superior and accurate forecasting model.

We believe that the outcome of this study would offer some meaningful insights to the existing literature, policy makers as well to the practitioners. The empirical results of this study would strengthen the theoretical framework of the determinants of exchange rates or stock market movement from the perspective of developing economies like India, which may be useful for the academic community. For the policy implication, it is hoped that our results would help the regulatory authority to better understand the stock and foreign exchange market behavior towards achieving the preferred monetary goals. Last but not the least, the practitioners, who deal directly with the stock or foreign exchange market, is interested in the relationship between the involved variables that can be profitably exploited.

The remainder of the paper is set out as follows. In Section 2, we describe daily exchange rates and, the concept of unit root tests, cointegration tests, linear granger causality framework and ARIMA models. In Section 3, we present our empirical results. Finally, Section 4 concludes the paper with some discussion on future research.

\section{Data and Methodology}

The data set comprises of daily closing price of S\&P CNX Nifty Index and INR/USD exchange rates obtained from the National Stock Exchange and Reserve Bank of India websites. The series span the period from $4^{\text {th }}$ January 1999 to $31^{\text {st }}$ August 2009 . The daily stock index and INR/USD returns are continuously compounded rate of return, computed as the first difference of the natural logarithm of the daily stock index and INR/USD exchange rate value.

\subsection{Estimation and Prediction}

To see how forecast performance is changing according to the choice of the forecasting sample periods is not only an interesting topic but also a meaningful trial to confirm the ro- 
bustness of the empirical results. In order to tackle the problems of sampling variation, this study uses a four validation set to examine the out-of-sample performance of VAR and ARIMA models. In particular, our study focused on VAR robustness, with respect to sampling variation. In the first validation set, daily data of Nifty and INR/USD from $4^{\text {th }}$ January 1999$31^{\text {st }}$ December 2006 was used. We divided the data into an estimation period (in-sample data) from January 4, 1999-December 31, 2005, and a forecast period (out-of-sample data), from January 1, 2006-31 ${ }^{\text {st }}$ December 2006. In the second validation set, we consider daily data from $4^{\text {th }}$ January $1999-31^{\text {st }}$ December 2007 . We conducted estimations over period from January 4, 1999-December 31, 2006 and data from January 1, 2007-31 ${ }^{\text {st }}$ December 2007 is reserved for the forecasting exercise. The third validation set covers a daily period from $4^{\text {th }}$ January $1999-31^{\text {st }}$ December 2008 . We divide the data into an estimation sample from January 4, 1999-December 31, 2007, and a forecast sample from January 1, 2008-31 ${ }^{\text {st }}$ December 2008. In the last validation set, we have used weekly data from $4^{\text {th }}$ January 1999-31 $1^{\text {st }}$ August 2009. The data is divided into two periods: January, 1999-December 2008 , used for model estimation and is classified as in-sample and period from January $1^{\text {st }}$ 2009-August $31^{\text {st }}, 2009$ are reserved for out-of-sample forecasting and evaluation.

\subsection{Unit Root Tests}

In order to test the unit roots i.e. stationarity in the S\&P CNX Nifty Index and INR/USD exchange rates, the study employ augmented Dickey and Fuller (ADF) test. In general ADF tests is represented as

$$
\Delta Y(t)=\rho_{0}+\rho Y(t-1)+\sum_{i=1}^{m} \Delta Y(t-i)+\varepsilon_{t}
$$

The testing for stationarity is formulated in the statistical hypothesis testing framework as a test of the null hypothesis is series is non-stationary and the alternative hypothesis is series is stationary.

Since the failure to reject the null of a unit root may be due to the low power of unit root tests against statioanrity alternatives, Kwiatkowski, Philips, Schmidt, and Shin (KPSS) proposed a test where the null is stationary and the alternate is a unit root. The results of ADF and KPSS test for the stock index and exchange rate series are reported in Table 1.

\subsection{Engle and Granger Cointegration Test}

In order to investigate the existence of long run relationship between two variables i.e. Nifty index and INR/USD exchange rates, we employ the Engle and Granger (1987) single equation methodology. We preferred to use this method rather than the Johansen Cointegration test is because of the simplicity of the Engle and Granger test and moreover, there are two variables under investigation, and hence there could be at most one cointegrating vector.

In first step, we would examine the order of integration of each variable. Cointegration between stock index and exchange rates requires that both the series should be of same order of integration. In Second step, we run the following cointegration regression.

$$
\ln S_{t}=\gamma_{0}+\gamma_{1} \ln E R_{t}+\varepsilon_{t}
$$


where $\ln S_{t}$ and $\ln E_{t}$ are log levels of S\&P CNX Nifty index and INR/USD exchange rates respectively.

The third step is to obtain the error terms and run the ADF and KPSS tests on the error terms. If the error series is stationary then null hypothesis of no-cointegrating vectors is rejected. The results of Engle and Granger cointegration test is presented in Table 2.

\subsection{Vector Autoregression Model}

The earlier section mainly emphasizes on the unit root tests, cointegration tests etc. This section presents the granger causality method to examining the dynamic (linear causal) relationship.

In bivariate case, the presence of granger causality is tested by investigating whether the past of one time series improves the predictability of the present and future of another time series. The study uses Vector Autoregression (VAR) model to examine the presence of linear granger causality. The benefit of VAR models is that they account for linear intertemporal dynamics between variables, without imposing a priori restrictions of a particular model.

A VAR model including S\&P CNX Nifty stock index returns and INR/USD exchange rates can be expressed as:

$$
\Delta \ln S_{t}=\alpha_{0}+\sum_{i=1}^{m} \beta_{i} \Delta \ln S_{t-i}+\sum_{i=1}^{m} \chi_{i} \Delta \ln E R_{t-i}+\varepsilon_{s e r}
$$

and

$$
\Delta \ln E R_{t}=\eta_{0}+\sum_{i=1}^{m} \mu_{i} \Delta \ln S_{t-i}+\sum_{i=1}^{m} \pi_{i} \Delta \ln E R_{t-i}+\mathcal{E}_{e r s}
$$

If cointegration exists between Nifty index and INR/USD series, then the granger representation theorem states that there is a corresponding error correction model. The error correction model for the Nifty index and INR/USD series can be represented as:

$$
\Delta \ln E R_{t}=\alpha_{0}+\delta z_{t-1}+\sum_{i=1}^{m} \mu_{i} \Delta \ln S_{t-i}+\sum_{i=1}^{m} \chi_{i} \Delta \ln E R_{t-i}+\varepsilon_{\text {ser }}
$$

where $Z=\ln S_{t}-\gamma_{0}-\gamma_{1} \ln E R_{t}$, are the residuals from the cointegration regression of the $\log$ levels and $\Delta \operatorname{lnS}_{\mathrm{t}}$ and $\Delta \operatorname{lnER}_{\mathrm{t}}$ are the log first difference of Nifty Index and INR/USD exchange rates respectively (or simple exchange rate returns and Nifty index returns).

Within the context of this VAR/VECM model, linear granger causality restrictions can be defined as follows: If the null hypothesis that $\chi$ 's jointly equal zero is rejected, it is argued that INR/USD exchange rate returns granger causes Nifty Index returns. Similarly, if the null hypothesis that $\mu$ 's jointly equal zero is rejected, Nifty returns granger cause exchange rate returns. If both of the null hypotheses are rejected, a bi-directional granger causality, or a feedback relation, is said to exist between variables. Different test statistics have been proposed to test for linear granger causality restrictions. To test for strict granger causality for pairs of $\left(\Delta \operatorname{lnS}_{\mathrm{t},} \Delta \operatorname{lnER}_{\mathrm{t}}\right)$ in this linear framework, a Chi-Square statistics is 
used to determine whether lagged value of one time series has significant linear predictive power for current value of another series. The results are presented in Table 3.

\subsection{ARIMA Model}

Popularly known as Box-Jenkins (BJ) methodology, but technically known as Autoregressive Integrated Moving Average (ARIMA) model, it is of the following form:

$$
Y_{t}=a_{0}+\sum_{i=1}^{p} \alpha_{i} Y_{t-i}+\sum_{i=0}^{q} \beta_{i} e_{t-i}+\xi_{t}
$$

where $Y_{t}$ is the time series and $\xi_{t}$ is an uncorrelated random error term with zero mean and constant variance and $a_{0}$ represents a constant term.

The correlogram, which are simply the plots of Autocorrelation Functions (ACFs) and Partial Autocorrelation Functions (PACFs) against the lag length, is used in identifying the significant ACFs and PACFs. The lags of ACF and PACF whose probability value is less than $5 \%$ are significant and are identified. The possible models are developed from these plots for the NIFTY Index returns series. The best model for forecasting is identified by considering the information criteria i.e. Akaike Information Criteria (AIC) and Schwarz Bayesian Information Criteria (SBIC).

\section{Results}

\subsection{Unit Root Test}

The results of Augmented Dickey Fuller and KPSS for the two series namely Nifty Index and INR/USD is shown in Table 1.

Table 1: Unit Root Test

\begin{tabular}{|l|l|l|r|l|}
\hline \multirow{2}{*}{\multicolumn{1}{|c|}{ Variable }} & \multicolumn{2}{c|}{ ADF Test } & \multicolumn{2}{c|}{ KPSS Test } \\
\cline { 2 - 5 } & \multicolumn{1}{|c|}{ t-statistics } & Critical Value & t-statistics & \multicolumn{1}{c|}{ Critical Value } \\
\hline $\ln \mathrm{S}_{\mathrm{t}}($ Log level) & -0.6553 & -3.4327 & 5.3562 & 0.739 \\
\hline$\Delta \ln \mathrm{S}_{\mathrm{t}}$ (First Diff) & -36.7465 & -3.4327 & 0.0890 & 0.739 \\
\hline $\ln \mathrm{ER}_{\mathrm{t}}$ (Log Level) & -1.3609 & -3.4327 & 0.7149 & 0.739 \\
\hline$\Delta \operatorname{lnER}_{\mathrm{t}}$ (First Diff) & -52.5394 & -3.4327 & 0.1765 & 0.739 \\
\hline
\end{tabular}

The results of ADF and KPSS test suggests that the log level of Nifty index and exchange rates series are non stationary. However, for the log first difference for the two series i.e. $\Delta \ln S_{\mathrm{t}}$ and $\Delta \operatorname{lnER} \mathrm{R}_{\mathrm{t}}$ is stationary. 


\subsection{Engle and Granger Cointegration Test:}

After testing for the unit root in the two series, we applied the two steps Engle and Granger cointegration tests on the log levels of the two series and tested its residuals for stationarity. The results of the cointegration regression are shown in Table 2.

Table 2: Engle and Granger Cointegration Test

\begin{tabular}{|c|c|c|c|}
\hline \multicolumn{4}{|c|}{ Cointegrating Regression } \\
\hline Coefficient & Coefficient Value & t-statistic & Probability \\
\hline$\gamma_{o}$ & 25.3729 & 40.3541 & 0.0000 \\
\hline$\gamma_{1}$ & -4.6699 & -28.2934 & 0.0000 \\
\hline \multicolumn{4}{|c|}{ Unit Root Test of Cointegrating Errors } \\
\hline \multicolumn{2}{|c|}{ ADF Test } & \multicolumn{2}{|c|}{ KPSS Test } \\
\hline t-statistics & Critical Value (1\%) & t-statistics & Critical Value (1\%) \\
\hline-0.5415 & -3.4327 & 5.4933 & 0.739 \\
\hline
\end{tabular}

In order to determine of the variables are actually cointegrated, the cointegration error terms are tested for stationarity. The results of ADF and KPSS tests clearly indicate that the error terms are nonstationary. The results also indicate that there is no long run relationship between exchange rate and stock indices for India. Thus, an error correction term need not be included in the granger causality test equations. The findings of Engle and Granger Cointegration tests are consistent with the findings of previous studies for developed markets such as the USA, the UK and Japan as well as for Asian market like India, Malaysia, Pakistan.

\subsection{Linear Granger Causality Test}

In order to investigate the dynamic relationship (linear granger causality) between Nifty index returns and INR/USD returns, we use the bi-variate VAR model without the correction term as specified in equation 1 and 2. The Swartz Bayesian Information Criterion (SBIC) is adopted to determine the appropriate lag lengths for VAR models.

Panel A of Table 3 reports the linear causal relationship between Nifty index returns and INR/USD returns while the panel B reports the linear causality results between volatility filtered Nifty index and INR/USD returns.

Table 3: Linear Granger Causality Test

\begin{tabular}{|l|c|c|}
\hline \multicolumn{3}{|c|}{ Panel A } \\
\hline Null Hypothesis & Chi-Sq-Statistics & P-Value \\
\hline Nifty Returns does not granger cause INR/USD & 8.2422 & $0.0162^{* *}$ \\
\hline INR/USD does not granger cause Nifty Returns & 9.6352 & $0.0081^{*}$ \\
\hline \multicolumn{3}{|c|}{ Panel B (After Volatility Filtering) } \\
\hline Null Hypothesis & Chi-Sq-Statistics & P-Value \\
\hline Nifty Returns does not granger cause INR/USD & 5.7282 & $0.0570^{* * *}$ \\
\hline INR/USD does not granger cause Nifty Returns & 8.7882 & $0.0123^{*}$ \\
\hline
\end{tabular}

* Represent the relationship being significant at $1 \%$

** Represent the relationship being significant at $5 \%$

$* * *$ Represent the relationship being significant at $10 \%$ 
The optimal lag length is 2 which are selected based on the SBIC criteria.

It is evident from the Panel A of Table 3 that the null hypothesis "Nifty Returns does not granger cause INR/USD" and "INR/USD does not granger cause Nifty Returns" is rejected. The Chi-Square statistics are significant and it provides the strong evidence for the argument that there is bidirectional linear granger causality between Nifty index and INR/USD returns.

We also investigated the dynamic relationship between the two variables after filtering out the volatility effects. Initially, we tested the two series for the ARCH effects. The result (available upon request) of the ARCH tests suggests that ARCH terms are present in both series. This suggests that there is need to re-examine the causality after removing the ARCH effects. Hence, we performed the linear granger causality tests using volatility filtered series of INR/USD and Nifty index returns. The results are presented in Panel B of Table 3. The causality tests again reveal that there is a bi-directional causality between the two variables.

In general, the results suggest that, exchange rate do help to explain changes in the stock index and stock index do help in explaining the changes in exchange rates. The causality is not due to volatility effects as we have also used volatility filtered series to investigate the dynamic relationship between the two variables. Thus the results of the study do not support the "Efficient Market Hypothesis". Moreover, the findings strongly support the portfolio approach on the relationship between exchange rates and stock prices. Thus, we could use stock price to forecast exchange rates.

\subsection{ARIMA Model}

The correlogram, which simply plots ACFs and PACFs against the lag length, is used to identify the significant ACFs and PACFs. Possible models are developed from the plots for INR/USD returns series. Information criteria (AIC and SIC) help identify the best forecasting model (results available upon request). After considering all possible models and looking at AIC and value of each model, it was decided that ARIMA $(2,1,1)$ is best model for forecasting daily returns of USD/JPY series for the first validation set (i.e. $1^{\text {st }}$ January $1999-31^{\text {st }}$ December 2006). Moreover, for the subsequent validation data sets, ARIMA $(1,1,2)$ is the best to forecast the daily returns of INR/USD exchange rates. Further diagnostic tests are performed to check the model's adequacy.

To check this, our study uses one of the popular diagnostic tests known as BreuschGodfrey LM Test. Here the test is used to check the presence of serial correlation in the residuals. It helps examine the relationship between residuals and several of its lagged values at the same time. The null hypothesis is that "there is no serial correlation". If the predictability value is greater than 5\%, then we accept the hypothesis (at $95 \%$ confidence levels); hence there is no serial correlation in the series. The LM Test for serial correlation of residuals suggests that the ARIMA $(2,1,1)$ and $\operatorname{ARIMA}(1,1,2)$ models capture the entire serial correlation; and the residuals do not exhibit any serial correlation (results available upon request). It suggests that the residuals, estimated by the two ARIMA models, are purely random. So another ARIMA model mayn't be searched (Gujrati, 1995). 


\subsection{VAR Model}

VAR model generally uses equal lag length for all the variables of the model. One drawback of VAR models is that many parameters need to be estimated, some of which may be insignificant. This problem of over parameterization, resulting in multicollinearity and a loss of degrees of freedom, leads to inefficient estimates and possibly large out-of-sample forecasting errors [Litterman, 1986, 30-36] and [Spencer, 1993, 415-419]. One solution, often adapted, is simply to exclude the insignificant lags based on statistical tests. Another approach is to use a near VAR, which specifies an unequal number of lags for the different equations.

In this study, while examining the causality test in the VAR framework, 2 lags of nifty index and INR/USD were selected based on SBIC criteria. However, when the parameters in VAR model of equation 3 are estimated, it is found that the $2^{\text {nd }}$ lag of Nifty and INR/USD seems to be insignificant. Thus, we exclude the $2^{\text {nd }}$ insignificant lags from the VAR model and re-estimated the model again using ordinary least square criteria. The forecasting performance of the two time series models and for the four out-of-sample period is summarized in Table 4.

Table 4: Prediction Accuracy

\begin{tabular}{|c|c|c|c|}
\hline \multirow{3}{*}{ Model } & \multicolumn{3}{|c|}{$1^{\text {st }}$ Validation Test Set $\left(1^{\text {st }}\right.$ Jan 2006 to $31^{\text {st }}$ December 2006) } \\
\hline & \multicolumn{3}{|c|}{ Performance Metrics } \\
\hline & MAE & RMSE & Directional Accuracy \\
\hline VAR & 0.002074 & 0.002986 & $53.13 \%$ \\
\hline ARIMA & 0.002081 & 0.002987 & $52.30 \%$ \\
\hline \multicolumn{4}{|c|}{$2^{\text {nd }}$ Validation Test Set ( $1^{\text {st }}$ Jan 2007 to $31^{\text {st }}$ December 2007) } \\
\hline Model & \multicolumn{3}{|c|}{ Performance Metrics } \\
\hline & MAE & RMSE & Directional Accuracy \\
\hline VAR & 0.002552 & 0.003861 & $56.61 \%$ \\
\hline ARIMA & 0.002555 & 0.003864 & $54.95 \%$ \\
\hline \multicolumn{4}{|c|}{$3^{\text {rd }}$ Validation Test Set ( $1^{\text {st }}$ Jan 2008 to $31^{\text {st }}$ December 2008) } \\
\hline Model & \multicolumn{3}{|c|}{ Performance Metrics } \\
\hline & MAE & RMSE & Directional Accuracy \\
\hline VAR & 0.004705 & 0.006885 & $53.13 \%$ \\
\hline ARIMA & 0.004759 & 0.006897 & $49.70 \%$ \\
\hline \multicolumn{4}{|c|}{$4^{\text {th }}$ Validation Test Set $\left(1^{\text {st }}\right.$ Jan 2009 to $31^{\text {st }}$ August 2009} \\
\hline Model & & Performance & Metrics \\
\hline & MAE & RMSE & Directional Accuracy \\
\hline VAR & 0.004772 & 0.006493 & $55.69 \%$ \\
\hline ARIMA & 0.004872 & 0.006673 & $48.10 \%$ \\
\hline
\end{tabular}

Financial time series modeling is primarily meant to determine how well forecasts from estimated models perform based on the unseen data, which is the out-of-sample data, using different performance measures. The forecasting accuracy statistics provide very conclusive results and shows that VAR model is superior over ARIMA.

A glance at the value of the RMSEs and MAE for the INR/USD exchange rate series suggests that VAR model is marginally better than the ARIMA model for the first three validation test period. However, for the $4^{\text {th }}$ validation test set, that there is superiority of VAR model over the ARIMA model. Compared to the ARIMA models, the VAR forecast have 
smaller RMSE and MAE values. Overall, results suggest that for all out-of-sample period, VAR gives better prediction that ARIMA models.

The VAR model also shows good directional forecasting ability, correctly predicting the direction of change between 53\% and 569\% over the four test samples. This means the forecasts are comparatively better than the chances in tossing a coin. Direction forecast accuracy for first, second, third and fourth validation sets was 53.13\%, 56.61\%, 53.13\% and $55.69 \%$ respectively. Hence, in terms of directional accuracy also, VAR model outperform the ARIMA model.

As for the forecasting stability, two observations can be made from Table 4. First, the time series models i.e. VAR is robust across the cross validation test and the forecasting results of VAR seems to be more stable. Second, no matter what method is used, there are no consistent patterns in RMSE within each forecast horizon across all out-of-sample periods. There is a difference in the values of various performance measures like RMSE and MAE of VAR and ARIMA models for all out-of-sample periods. This result is expected since the structure of the exchange rate time series varies from one time period to the other. If in-sample data have a general increasing trend while the out-of-sample is in a general downward direction or vice versa, then it is clear that none of the forecasting methods can predict well particularly in the short run, leading to large variations in prediction. Thus, it may be concluded that the predictive accuracy of all the models changes across time for different forecasting horizon.

\section{Conclusion}

In this study, an attempt has been made to examine the dynamic (causal) relationships between S\&P CNX Nifty index returns and INR/USD exchange rate returns for the Indian market. Our study uses the ADF and KPSS tests to examine the unit root in the series and Engle and Granger test to check the long run relationship between the two variables. The results of cointegration test suggest that there is no long run relationship between the two variables.

We also used the traditional linear granger causality tests to examine the dynamic relationship between index returns and exchange rate returns. The evidence suggests the bidirectional causality from index returns to exchange rate returns and from exchange rate returns to index returns. Thus the results provide the evidence for the presence goods market or portfolio approach.

Moreover, the study also develops a VAR based forecasting model by exploiting the dynamic relationship between the exchange rates and stock index. The VAR model was benchmarked against traditional forecasting techniques, like the ARIMA model, to determine any added value to the forecasting process. A cross-validation scheme is employed to examine the robustness of the two models with regard to sampling variation and structural changes in time series. Out-of-sample performances of the two models were evaluated along four criteria, MAE, RMSE and Directional Accuracy. Results from the study indicate that the VAR model achieves high rate of accuracy, in terms of MAE, RMSE and Directional Accuracy for the four validation sets.

The results imply the market inefficiency and lend support to the technical analysis. The market participants may consider the relationship between the exchange rate and stock index to predict the future movement of exchange rate effectively. Moreover, the results can help the regulators to understand the structure of the market in a better way and then design the policy. In terms of policies relevance, the regulators in India should be very careful in 
conducting exchange rate policies or capital market polices as it may impact on the development of the financial markets.

It is expected that the findings in this paper will set a standard for further studies in this field. For example, the paper considers only linear models, but there have been recent studies that consider nonlinear models to reflect nonlinearities in deviations of the spot exchange rate from economic fundamentals. To extend the study in this direction various nonlinear models can be developed and their accuracy can be accessed. There is also a scope to assess the model's accuracy, while taking into account the set of potential macroeconomic input variables such as interest rates, consumer price index and industrial production, as well as technical indicators. So we preferably conclude that VAR is a superior model, which can be resourcefully explored by economists and forecasters.

\section{References}

Ai-Yee Ooi, Syed Azizi Wafa Syed Khalid Wafa, Nelson Lajuni, Mohd Fahmi Ghazali., "Causality between Exchange Rates and Stock Prices: Evidence from Malaysia and Thailand", International Journal of Business and Management, 4(3), 86-98,2009.

Alexander, D., L.R. Thomas, "Monetary/Asset models of exchange rate determination: How well have they performed in the 1980's?" International Journal of Forecasting, 3, 53-64, 1987.

An-Pin Chen, Yu-Chia Hsu, Ko-Fei Hu., "A Hybrid Forecasting Model for Foreign Exchange Rate Based on a Multi-neural Network," icnc, 5, 293-298, Fourth International Conference on Natural Computation, 2008.

Aydemir, O. ve E. Demirhan., "The Relationship between Stock Prices and Exchange Rates: Evidence from Turkey", International Research Journal of Finance and Economics, 23, 207-215, 2009,

Tabak, T. B., "The Dynamic Relationship between Stock Prices And Exchange Rates: Evidence For Brazil," International Journal of Theoretical and Applied Finance, 9(08), 1377-1396, 2006.

Brooks, C., "Linear and Nonlinear (Non-) Forecastability of Daily Sterling Exchange Rates," Journal of Forecasting, 16, 125-145, 1997.

Chen, A.S. M.T. Leung., "Regression neural network for error correction in foreign exchange forecasting and trading," Computers and Operations, 31(7), 1049-1068, 2004.

Corte, D. P., L. Sarno, and I. Tsiakas. "An Economic Evaluation of Empirical Exchange Rate Models: Robust Evidence of Predictability and Volatility Timing", Working paper, University of Warwick, 2007.

Doong, Shuh-Chyi, Yang, Sheng-Yung and Wang, Alan T., "The Dynamic Relationship and Pricing of Stocks and Exchange Rates: Empirical Evidence from Asian Emerging Markets", Journal of American Academy of Business, Cambridge 7 (1), 118-123, 2005.

Gandolfo, G., Padoan, P.C., G, Paladino., "Exchange rate determination: single equation or economywide models? A test against the random walk", Journal of Banking and Finance, 14, 965-992, $1990 \mathrm{~b}$.

Gandolfo, G., Padoan, P.C., G, Paladino., "Structural models versus random walk: the case of the lira/\$ exchange rate", Eastern Economic Journal, 16, 101-113, 1990 a.

Gençay, R., "Linear, Non-linear and Essential Foreign Exchange Rate Prediction with Simple Technical Trading Rules", Journal of International Economics, 47, 91-107, 1999.

Hong., Y and Tae-Hwy Lee, "Inference on Predictability of Foreign Exchange Rates via Generalized Spectrum and Nonlinear Time Series Models," The Review of Economics and Statistics, MIT Press, 85(4), 1048-1062, 2003. 
Hsieh, D. A., "Testing for nonlinear dependence in foreign exchange rates", Journal of Business, 62(3), 339-368, 1989.

Kuan, C.M. and T. Liu., "Forecasting exchange rates using feedforward and recurrent neural networks, "Journal of Applied Econometrics, 10 (4), 347-364, 1995.

Leung, M. T., Daouk, H., A. A. Chen., "Forecasting stock indices: a comparison of classification and level estimation models", International Journal of Forecasting, 16, 173-190, 2000.

Litterman, Robert B., "Forecasting with Bayesian Vector Autoregressions Five Years of Experience", Journal of Business and Economic Statistics, 4 (1):25-38, 1986.

Manish K, and M. Thenmozhi., "Forecasting Daily Returns of Exchange Rates Using Artificial Neural Network and ARIMA Model", ICFAI Journal of Applied Finance, 10(11), 16-36, 2004.

Manish., K and M. Thenmozhi, "Static and Dynamic Neural Network in Forecasting Exchange Rate Returns", in: Proceedings of conference on Research in Finance and Accounting, IIM Lucknow, India, 2005

Meese, R., K, Rogoff., "Exchange rate Model of the Seventies: Do They Fit Out of the Sample?", Journal of International Economics, 14, 3-24, 1983 a.

Meese, R., K, Rogoff., "The Out of sample Failure of empirical Exchange rate Model: sampling error of Misspecification?" In: Freintel J., Ed. Exchange Rate and International Macroeconomics, Chicago University Press, 1983 b.

Baillie, N. R. P. McMahon., The foreign exchange market: Theory and econometric evidence. Cambridge University Press, Cambridge, 1989.

Pan, M.S., Fok, R.C.W. and Liu, Y.A., "Dynamic linkages exchange rates and stock prices: Evidence from Pacific Rim countries", Working Paper at College of Business Shippensburg University mimeo, 2001.

Panda, C., V. Narasimhan., "Forecasting daily foreign exchange rate in India with artificial neural network", The Singapore Economic Review, 48(2), 181-199, 2003.

Phylaktis, K. F. Ravazzolo., "Stock Prices and Exchange Rate Dynamics", Journal of International Money and Finance, 24, 1031-1053, 2005.

Qi, Min, Yangru Wu "Nonlinear Prediction of Exchange Rates with Monetary Fundamentals," Journal of Empirical Finance, 10(5), 623-640, 2003.

Rime, D., L. Sarno and E. Sojli., "Exchange Rate Forecasting, Order Flow and Macroeconomic Information”, Norges Bank Working Paper Series ANO 2007/2, 2007.

Sarantis, N., C. Stewart., "Monetary and asset market models for sterling exchange rates: a cointegration approach", Journal of Economic Integration, 10, 335-371, 1995 a.

Sarantis, N., C. Stewart., "Structural, VAR and BVAR models of exchange rate determination: a comparison of their forecasting performance", Journal of Forecasting, 14, 201-215, 1995, b.

Schinasi, G. J, P. A. Swamy., "The out-of-sample forecasting performance of exchange rate models when coefficients are allowed to change". Journal of International Money and Finance, 8, 373390, 1989.

Spencer, David E., "Developing a Bayesian Vector Autoregression Model", International Journal of Forecasting, 9, 407-421, 1993.

Vygodina, Anna V., "Effects of size and international exposure of the US firms on the relationship between stock prices and exchange rates", Global Finance Journal 17, 214-223, 2006.

Weigend, A.S., B.A. Huberman and D.E. Rumelhart., "Generalization by weight-elimination with application to forecasting, ” In: Lippman, R.P., Moody, J.E. and D.S. Touretzky (Eds), Advances in Neural Information Processing Systems, 3, Morgan Kaufman, San Mateo, CA, 875-882. 1991.

Woo, Wing, T., "The Monetary Approach to Exchange rate determination Under rational Expectations", Journal of International Economics, 18, 1-16, 1985. 